\title{
GEOGRAFSKI PRISTOPI K PROUČEVANJU KRIZNIH OBMOČlJ
}

\author{
Jernej Zupančič \\ Oddelek za geografijo, Filozofska fakulteta, Univerza v Ljubljani, Aškerčeva 2, \\ SI- I000 Ljubljana \\ e-mail: jernej.zupancic@guest.arnes.si
}

Izvirni znanstveni članek

COBISS 1.01

\section{Izvleček}

Prispevek obravnava pojav kriznih območij v svetu v luči mednarodnih odnosov in preoblikovanja svetovne politične karte. Na podlagi analize fiziognomije, strukture in funkcij teh pokrajin ugotavlja razloge nastanka kriznih območij, podaja značilni potek razvojnih faz in predvsem družbenih ter prostorskih posledic. Le-ta se pogosto obnavljajo in predstavljajo relativno trajna geopolitično nevralgična območja. To so presečišča številnih interesov, čeprav so po svoji strukturi predvsem svetovna periferija. Prispevek predvsem poudarja geografske vidike proučevanja kriznih območij. Na primerih severne Dalmacije na Hrvaškem in Kosova v južni Srbiji ilustrira potek dveh različnih kriznih območij.

Ključne besede: politična geografija, krizna območja, narodno vprašanje, medetnični odnosi, Jugovzhodna Evropa.

\section{GEOGRAPHICAL ATTEMPTS TO RESEARCH OF CRISIS AREAS}

\begin{abstract}
The paper deals on the phenomenon of crisis areas in the world in the light of international relations in transformation of world political map. Analysing the physiognomy, structures and functions the paper is seeking the reasons for the conflicts, describe their genesis, characteristical developmental stages and particulary the spatial and social consequences. Those mostly regenerate their conflictual potential and are relatively constant geopolitcial neuralgic areas. They are the crossroads of world-power interesses, even they are poor world periphery by their structure. The paper undertake the geographic point of research of crisis areas. The shown cases of North Dalmatia (Croatia) and Kosovo (South Serbia) the author ilustrate the characteristical development of two different crisis areas.
\end{abstract}

Key words: political geography, crisis areas, ethnic question, interethnic relations, Southeast Europa. 


\section{UVOD}

Zadnjo dekado 20. stoletja označujejo burni geopolitični pretresi, ki so v svojih posledicah bistveno spremenili svetovno politično karto. Predvidljivost ideološko, vojaško, gospodarsko in kulturno polariziranega sveta je ob hkratnem nastopu informacijske družbe zamenjala dinamika novega ustvarjanja globalnih ravnovesij med svetovnimi silami, ki so $\mathrm{v}$ iskanju novega svetovnega političnega reda $\mathrm{v}$ svojih robnih interesnih conah posredno ali neposredno sprožili vrsto spopadov. Popularni slogan o »globalni vasi« v kateri se med vsemi dejavniki ustvarjajo odnosi vzajemnosti in soodvisnosti je implicitno ustvarjal vtis, da morajo nove interakcije na našem planetu skorajda pogojevati večjo skrb in odgovornost za mir in razvoj v svetu. Vendar je bilo povsem nasprotno. Prah padlega berlinskega zidu, ki je pol stoletja, simboliziral razdeljenost razvitega sveta na »zahodni« in »vzhodni«, se še ni polegel, ko se je odprla nova fronta: nastop koalicijskih sil proti Iraku zaradi agresije na sosednji Kuvajt. Čeprav je bil to eden prvih konsenzov ključnih svetovnih sil, je rezultat prav klavrn: Irak je še vedno krizno žarišče. Še celo več: vsi nadaljnji ukrepi so odnose navznoter in navzven na širšem območju Bližnjega vzhoda samo še dodatno zapletali ter širili območje konfliktov. V dobi informacijske družbe, globalizacije svetovnih gospodarskih in kulturnih tokov in integracije kot poglavitne tendence političnih odnosov je število različnih konfliktov hitro naraščalo. Brez zadrege bi zato smeli imenovati naš čas tudi »doba kriznih žarišč«.

Naraščajočo dinamiko svetovnih procesov je spremljala tudi politična geografija. Čeprav gre za eno izmed središčnih tematik te geografske veje, so bili pristopi dokaj različni. Najpogosteje so se je lotevali z vidika spreminjanja poteka in vloge političnih meja ter odnosom med središčem in periferijo. Nasploh je politično geografijo, ki je v zadnjih dveh desetletjih 20. stoletja doživela nagel razcvet in se razširila v večino držav (prej je bila ta disciplina dokaj omejena!), promovirala predvsem tematika spreminjajoče se vloge političnih meja. Med klasična tovrstna dela sodi knjiga J. Minghija in D. Rumleya (Rumley \& Minghi, 1991). Ni dvoma, da so k temu največ prispevali procesi evropskega združevanja in povezovanja oziroma integracija kot svetovni proces. Vendar se je ob tem zlasti zaradi dezintegracije nekaterih dotlej večnacionalnih držav v ospredje postavljalo tudi narodno in manjšinsko vprašanje. Vprašanje kriznih žarišč so obravnavale predvsem nekatere bolj globalno orientirane političnogeografske šole, posebej britanska in ameriška. Razvoju in problemom kriznih območij se je zlasti evropska politična geografija posvečala sorazmerno malo. Nasprotno so te »klasične« političnogeografske vsebine postale predmet znanstvene obravnave v nekaterih družboslovnih vedah, posebej v študijah obramboslovja, vojaških ved, mednarodnih odnosov, pa tudi modernega zgodovinopisja. Zato se geografi, tudi ko bi želeli podrobneje proučiti regionalne vidike držav oziroma območij, ki jih je zajela kriza, znajdejo pred nemajhno dilemo: kateri je poglavitni dejavnik oblikovanja kriznega območja in drugič, kako (in kje) iskati prihodnje perspektive. Pomanjkanje metodološkega instrumentarija in tudi zgledov pelje v preveč enostranske sodbe. Neredko zato tudi geografi, sledeč zgledu iz literature in zato naslanjajoč se seveda zgolj »politične « dejavnike, skoraj povsem izpuščajo »geografske« elemente in zanemarjajo kompleksnost analize kriznih območij. Čas je torej, da nekoliko obširneje spregovorimo o geografskih vidikih proučevanja kriznih območij. Prav geografija je zaradi svojega kompleksnega pristopa ter empiričnega spoznavanja problemov 
na ravni manjših enot še posebej primerna tako za podrobno analizo kakor (na tej podlagi) za iskanje prihodnjih družbeno-prostorskih konstrukcij. Namen tega prispevka je podati nekaj smernic za bolj sistematičen pristop k raziskovanju kriznih območij ter prispevati k boljšemu razumevanju burnih geopolitičnih procesov na regionalni in globalni ravni.

\section{POJAV, RAZŠIRJENOST IN LASTNOSTI KRIZNIH OBMOČIJ}

Nedavno so bili v Geografskem obzorniku objavljeni nekateri vidiki pojava in razvoja kriznih območij (Zupančič, 2005, 6-7). Tokrat bomo opozorili predvsem na analitične vidike raziskovanja teh posebnih, toda razmeroma obširnih območij.

Krizna območja so tista območja zemeljskega površja, ki so predvsem zaradi družbenih dejavnikov doživela naglo poslabšanje gospodarskega stanja, dramatične spremembe starostne, spolne, narodne sestave ter geografsko razporeditev prebivalstva, zaostritev odnosov med različnimi skupinami prebivalstva ter nastanek konfliktov, izolacijo gospodarskih in kulturnih tokov in odnosov ter podobno. Ta območja so torej v kratkem času doživela nagle fiziognomske, strukturne in funkcijske spremembe z izrazito splošno tendenco poslabšanja. Ni jih težko prepoznati, saj imajo krizna območja vrsto lastnosti, po katerih se ločijo od ostalih ozemelj. Nanje navadno opozarjajo posledice spopadov (ruševine v naseljih v prometnicah, druge sledi bojev), kaotično pravno stanje, anarhija v delovanju javnih ustanov (ali sploh njihova odsotnost), prevlada črnega trga in različnih nelegalnih gospodarskih operacij, odsotnost investicij, beg kapitala in različnih gospodarskih dejavnosti, zelo nizka raven osebne in kolektivne varnosti, pogosto uporabljene oblike represije, prisotnost različnih paravojaških skupin, naglo povečana smrtnost in zmanjšana rodnost, množične selitve, pojav beguncev, odsotnost ali močna redukcija delovanja izobraževalnega sistema ter zdravstvenega in socialnega varstva. Način življenja je radikalno spremenjen: prebivalstvo se prilagaja trenutnim možnostim preživetja. Načrtovanja je malo ali skoraj nič, zato je tudi prostorski razvoj pretežno stihijski. Številnih storitvenih dejavnosti (posebej zavarovalništva in bančništva) praktično ni. Krizna območja so dejansko, nekatera pa tudi pravno izločena iz svetovnih tokov (različne oblike sankcij). Veliko kriznih območij preide pod mednarodni nadzor mirovnih sil ali tudi mirovnih vojaških operacij. Krizna območja so torej na različne načine odvisna ozemlja: vojaško-varnostno (mirovne operacije in vzdrževanje miru), gospodarsko (prejemniki pomoči humanitarnih organizacij in misij) in politično (tuji nadzor nad razvojem odnosov med različnimi skupinami prebivalstva) (več glej v: Imbusch, Zoll, 1999). Krize so dinamična, a zelo pogosto razmeroma dolgo trajajoča stanja; pregled po kriznih žariščih sveta kaže v poprečju na več desetletno trajanje konfliktov in njihovih posledic (Zupančič, 2005, 5).

Krizna območja zavzemajo danes obsežne površine. Celo v Evropi zavzemajo površje vsaj poprečno velike evropske države. Bosna in Hercegovina, deli južne Srbije s Kosovim, zahodna Makedonija, deli Moldavije in Albanije, predeli na Cipru, ne nazadnje pa tudi Severna Irska, baskovske province v Španiji in tudi območja nekdanjih srbskih »krajin« na Hrvaškem kažejo značilne lastnosti kriznih in konfliktnih ter postkonfliktnih območij(Schneckener, 2002). Ob tem ne smemo pozabiti, da so bile evropske države še pred dobrega pol stoletja predvsem »krizne«; dediščina dveh svetovnih vojn se je močno poznala v regionalni fiziognomiji in 
strukturi, da o funkcijah niti ne govorimo. O slednjih govori obsežno Tunjićevo delo, ko ob analizi evropskih meja ugotavlja njihovo konstantno konfliktnost in kontradiktornost: po eni strani meje varujejo organizirane človeške družbe (narode) v okviru njihovih nacionalnih držav, po drugi pa so zaradi nezadovoljstva s potekom mejne črte prav zaradi te $\mathrm{v}$ pogostih sporih (Tunjić, 2004, 15-21). Razlike med njimi so sicer zelo velike, kar samo poudarja individualnost vsake izmed omenjenih pokrajin. Glavnina kriznih območij se nahaja v državah t.i. »tretjega sveta«: v Afriki, Aziji in Latinski Ameriki (Nohlen, 2000). Najobsežnejše praktično sklenjeno krizno območje obsega pas od Palestine do vzhodne Azije in zajema pri tem najstarejša, najbolj zapletena, ter gospodarsko, politično in ideološko najbolj kompleksna območja, za katera je izraz »vozlišča sveta« še kako ustrezen (Fromkin, 2001). Njegovo izhodišče je v Palestini, kjer so srečujeta in spopadata gospodarsko uspešna židovska država s sosednjimi mnogo revnejšimi arabskimi območji in je obenem stičišče treh monoteističnih religij: židovske, krščanske in islamske (Reinhart, 2002; Steininger, 2003). Nadaljuje se v multikulturno okolje Libanona in prek sirskega ozemlja na danes najbolj razvpito krizno območje Iraka (Hiro, 2003) in Perzijskega zaliva (Atlas of the Middle East, 2003). Severni krak seže $v$ vzhodno Turčijo in predele, naseljene s kurdskim prebivalstvom. Tam se še vedno odvijajo občasni spopadi s kurdskim gverilskim gibanjem (PKK- kurdsko delavsko stranko) (Strohmeier, 2000). Poselitveno območje Kurdov sega do Kavkaza, ki je drugo veliko vozlišče kultur, ideologij in strateških interesov in eno izmed najstarejših kriznih žarišč. Izredno pestro etnično in versko sestavo prebivalstva so dodatno zapletle sovjetske oblasti z oblikovanjem različnih političnih enot (Gilbert, 2002; Kappler, 2001; Grobe-Hagel, 2001). Prav tu se kaže tesna povezanost konfliktnosti lokalnih skupnosti in vplivanja velikih sil (Grošelj, 2006, 28-29). Onstran Kaspijskega morja in Irana, ki spričo posebnosti svojega razvoja zadnjih 30 let zasluži oznako kriznega območja, z arabskimi, azerbajdžanskimi, kurdskimi, hazarskimi, in drugimi etničnimi elementi pa neposredno posega vanje. Vzhodna soseda - Afganistan - se z neprekinjenimi vojnami in notranjimi spopadi sooča nad tri desetletja (Ewans, 2001). Navezuje se na Pakistan na vzhodu, ki je v svojem severnem delu - Kašmirju - soočeno s prav tako desetletja trajajočimi konflikti. Le ti so tako notranje pogojeni (razmerja med religiozno opredeljenimi skupinami) kakor (in danes še posebej) odvisne od skoraj klasične podobe spopadanja za ozemlje, ko si nasproti stojita veliki, populacijsko močni državi Indija in Pakistan (Lozinšek, 2004, 12-13). Vzhodno od Afganistana se čedalje bolj poglablja krizo v nekdanjih republikah sovjetske osrednje Azije, še posebej v Tadžikistanu in Kirgizistanu (Natek, 2000) in še dalje proti območju Bajkalskega jezera.

Ostala krizna območja v Aziji so razporejena bolj točkasto. Predeli v Asamu (Indija), na severnem Cejlonu sodi med razmeroma dolgotrajna krizna žarišča. Mjanmar (nekdanja Burma) sodi med krizna območja zaradi radikalnega totalitarnega režima, ki je povzročil hudo revščino. Kambodža si še ni opomogla od državljanskih vojn. V Indoneziji je nedavni potres in nato cunami le poglobil krizo na severozahodu Sumatre (Aceh). A območje ni edino, saj so pretresi značilni tudi za Borneo (Dajak) ter za Celebes in sosednje Moluke. Blizu je območje najjužnejšega filipinskega otoka Mindanaa $\mathrm{z}$ radikalno muslimansko gverilo. Timor je na drugem koncu velikega južnoazijskega otočja pred nekaj leti pričel sanirati dolgotrajno krizo. Poseben primer je vsekakor Severna Koreja, prizadeta zaradi totalitarnega komunističnega režima, ki grozi biti eno svetovno izredno odmevnih kriznih žarišč (Smith, 2003). Posebni 
primeri so gotovo tudi Tibet in ne dosti manj težavno, čeprav mnogo manj znano, tudi v pokrajini Uighur na Kitajskem: zatiranje manjšin (pravzaprav celih narodov) s strani kitajske državne politike.

Afriški kontinent ima zaradi posebnosti svojega novejšega zgodovinskega razvoja kar nekaj posebnosti, zaradi katerih sedaj predstavlja najobsežnejše, toda še zdaleč ne najbolj odmevno in poznano območje sicer različnih kriznih žarišč. Kolonialna razdelitev je pustila meje, ki so potem postale državne oziroma mednarodne meje. Na razporeditev ljudstev, jezikov in kultur se niso ozirale. Družbenih razvoj afriških ljudstev s poudarjeno modernizacijo je v drugi polovici 20. stoletja vendarle privedel do sorodnih procesov, kot jih je Evropa preživela dobro stoletje poprej: iz ljudstev so se pričeli oblikovati narodi (Jambrek, 1980; Vejnović, 1971). Številna medplemenska tradicionalna nasprotja so vešče izrabljale kolonialne sile, ki so po načelu »deli in vladaj« z razmeroma skromnimi vojaškimi silami obvladovale ključne točke in območja v kolonijah. Obdobje dekolonizacije pa je časovno sovpadalo z zaostrovanjem hladne vojne. Nemirna afriška tla so bila pogosti poligoni političnih in gospodarskih poizkusov ureditve bolj »zahodnih« - se pravi kapitalističnih, ali pa na drugi strani različnih socialističnih poizkusov. Po razpadu blokovske razdelitve so ideološko polarizacijo nadomestili strateški vplivi multinacionalnih družb, ki so skupaj s svojim strateškim zaledjem pričele dodatno zapletati že tako napete odnose v nekaterih območjih (Huchthausen, 2003). Tako kažejo močan vpliv poleg že uveljavljenih družb iz evropsko-ameriškega območja zlasti kitajski in različni islamski (zlasti naftni) lobiji, ki sponzorirajo zlasti različna fundamentalistična gibanja. Pas nemirnega kriznega afriškega sveta se tako vleče od zahodne afriške obale in vključuje Liberijo, Siera Leone, Slonokoščeno obalo, Gano, Mali, Niger, Čad, Burkino Faso, zelo blizu konfliktom pa je ponovno tudi Nigerija. Proti jugu sledijo države s preteklimi osebnimi diktaturami (kot na primer Centralnoafriška republika), na vzhodu pa zlasti Sudan in vse do »afriškega roga« (Etiopija z Ogadenom in celotna Somalija). A tu se ne konča, temveč se prek jezerskega višavja (Uganda, še posebej pa Burundi in Ruanda ter območja v Zairu (Ituri) nadaljuje proti jugu. Obe nekdanji portugalski koloniji Angola in Mozambik sta po dekolonizaciji doživljali dolga leta državljanske vojne in imata sedaj (posebej Angola) temu ustrezne posledice. Krizna območja v Afriki so bila in so še vedno v precejšnji medijski senci, strukturno so te države navadno v razsulu in zato prepuščene samim sebi (Smith, 2003; Nohlen, 2000). Mirovne operacije so bile redkejše, po obsegu skromnejše in zato malodane vse po vrsti neuspešne. Za vojaške spopade in s tem povezane nastanke kriznih območij na »črni« celini so odločilnega pomena po eni strani kričeča socialna nasprotja in predvsem prevlada revščine, po drugi pa iskanje ustreznejših državnih okvirov (Prebilič, 2006, 28-29).

Krizna območja v srednji in Južni Ameriki temeljijo predvsem na velikanskih socialnih razlikah, ki predstavljajo ugodno okolje za različne diktatorske poizkuse ter revolucije. Na jugu Mehike so se v pokrajini Chiapas uprli Indijanci, Gvatemala je preživela večletno državljansko vojno, prav tako Honduras (Fischer Weltalamanch, 2004, Brown, 1985). Revolucionarni prevrati so uspeli za dalj časa edino na Kubi, medtem ko so v Nikaragvi in Salvadorju povzročili veliko opustošenje. V Panami totalitarni obrat ni uspel, a povzročil je hudo gospodarsko krizo. Nesporno najrevnejša država zahodne hemisfere je Haiti, prva črnska republika (1804!), ki pa se otepa z vedno novimi diktaturami. Slednje so bile značilna poteza tudi mnogih južnoameriških držav: Čila, Argentine, Bolivije, Peruja, Paragvaja. V Kolumbiji 
je regionalno močna prevlada mafijskih kartelov, proti katerim vojaško posegajo vladne sile. Venezuela preživlja težko gospodarsko krizo, v Peruju pa se občasno javlja radikalno "maoistično« gibanja Sendero Luminoso (svetla pot). Za razliko od afriških in azijskih kriznih območij so ta v Latinski Ameriki (Smith, 2003) teritorialno nekoliko težje določljiva in bolj podvržena periodični intenzivnosti. Zato tudi niso doživela večjih mirovnih operacij.

Točen obseg kriznih območij je sicer težko določiti. Danes ga ocenjujemo na okrog 18 milijonov km2 (skoraj dve Evropi), na katerih prebiva okrog 450 milijonov ljudi. Mnogi doživljajo usodo begunstva - po podatkih visokega komisariata za begunce jih je bilo leta 2003 dobrih 37 milijonov; vendar je številka verjetno še višja (Fischer Weltalmanach, 2005). Gre torej za vse prej kot malenkostna razmerja na svetovni ravni. Krizna območja predstavljajo tudi velik strošek svetovne organizacije, saj so stroški leta 2003 samo za mirovne operacije dosegli skoraj 3 milijarde ameriških dolarjev. Samo Visoki komisariat za begunce pri OZN zaposluje okrog 4500 ljudi, letni stroški pa znašajo okrog 1,9 milijarde ameriških dolarjev. Vendar je globalni učinek kriznih območij predvsem v njihovem geostrateškem pomenu: so vozlišča in presečišča svetovnih interesov, preizkusna polja novih strategij in braniki kultur. Na njih, ob njih in mestoma celo zaradi njih se pojavljajo nove doktrine. Tam so se brusile in krhale velesile $\mathrm{v}$ obdobju blokovske razdelitve sveta, danes pa se uveljavlja nov (predvsem ameriški) svetovni politični red, krepijo povezave na kulturni ravni (zbliževanje predvsem držav s pretežno islamsko versko in kulturno podlago), rastoč ekonomski (in dalje tudi politični) vpliv Kitajske. Krizna območja so svetovna periferija za tamkaj živeče prebivalstvo, toda hkrati stičišče globalnih sil, strategij in interesov z zelo daljnosežnimi učinki na skoraj celem svetu.

\section{RAZVOJ KRIZNEGA OBMOČJA, POSTKONFLIKTNA STANJA IN KONFLIKTNI POTENCIAL}

Krizna območja imajo kljub njihovi poudarjeni individualnosti vrsto skupnih potez. Potek krize ima nekatere značilne razvojne faze. Te so (Zupančič, 2005, 9):

1. Pojav strukturnih neravnovesij in ustvarjanje napetosti (faza zapletanja).

2. Incident; enkraten dogodek ki pomeni mejo med mirom in spopadi.

3. Izbruh krize: naglo in dramatično poslabšanje videza, strukture in funkcije neke pokrajine.

4. Faza skrivanja in zanikanja ob hkratnem domačem »gašenju« konflikta.

5. Internacionalizacija: formalno priznanje krize in poziv $\mathrm{k}$ mednarodnim vidikom reševanja.

6. Intervencija: obsega časovno kratko ustvarjanje in precej daljše vzdrževanje miru.

7. Sanacija: ukrepi in postopki, ki vodijo k umiritvi razmer in odpravi vzrokov krize.

8. Revitalizacija: obnova potencialov in integracija $\mathrm{v}$ regionalno in globalno okolje.

Čeprav mnoga krizna območja, ki so se pojavila v obdobju po drugi svetovni vojni, še niso doživela uspešne revitalizacije, je vztrajanje mednarodnih dejavnikov, začenši z Varnostnim svetom OZN, vendarle porok načelnega hotenja po izboljšanju razmer in končanju kriz in 
konfliktov. Zdi se, da mnoga krizna območja ostajajo latentna žarišča. Možnosti ponovne politične recesije s konflikti in destruktivnimi procesi ostaja trajna opcija. V tem kontekstu se je treba vprašati predvsem o problemih: o konfliktnem potencialu in o postkonfliktnih stanjih.

Za postkonfliktna stanja označujemo tiste situacije in okoliščine, kjer je po določenem trajanju konfliktov in torej vztrajanju kriznega območja prišlo do pomiritve in tvorne rekonstrukcije življenja: območje je postalo urejeno, vključeno v mednarodno delitev dela in promet, velika večina neposrednih posledic spopadov so že odstranili. A vendar vseh posledic ni mogoče hitro in enostavno rešiti. Nekatera območja so tako zaradi selitev prebivalstva vsaj začasno ostala močno depopulacijska; tak primer je območje nekdanjih Kninskih krajin na Hrvaškem, kjer je zaradi množičnega eksodusa Srbov pokrajina ostala skoraj prazna in tudi zaradi zapletenih pravnih postopkov brez resnih možnosti izgradnje sodobne tehnične in družbene infrastrukture.

Dejansko pomenijo postkonfliktna stanja mnogokrat (a nikakor ne vedno!) še vedno opazen konfliktni potencial. Tega je mogoče ocenjevati tudi tam, kjer doslej do konfrontacij, odprtih konfliktov in resnih kriznih situacij še ni prišlo. Čeprav o tem postavljajo nekateri avtorji tudi povsem empirične koncepte ugotavljanja konfliktnosti (glej Tunjić, 2004, 344-346), so napovedi o izbruhih kriz in njihovega značilnega poteka še vedno precejšnja neznanka. Toda dejstvo je, da območja z več etnično-politično opredeljenimi skupnostmi, območja labilnih političnih meja, območja dragocenih naravnih in ustvarjenih virov, predstavljajo precej pogosto tarčo pritiskov, iz katerih se pozneje lahko razvijejo konflikti in izbruhnejo krize.

\section{GEOGRAFSKA ANALIZA KRIZNIH OBMOČIJ}

Spoznavanje kriznih območij sodi v t.i. »problemsko« politično geografijo. Krizna območja imajo kljub velikim medsebojnim razlikam in torej izraziti individualnosti teh pokrajin nekatere (maloprej kratko omenjene) skupne značilnosti, ki nam precej olajšajo analizo zapletov, poteka in posledic konfliktov in tako prispevajo $\mathrm{k}$ razumevanju strukturnih značilnosti konfliktnih in postkonfliktnih stanj.

Nedvomno je prvi korak prepoznavanje kriznega območja. Opredelimo ga na podlagi značilnih pojavov v fiziognomiji (na primer ruševine, sledi spopadov ipd.), strukturi (velike in nagle negativne demografske spremembe, spremenjen način poselitve ipd.) ter funkciji pokrajine (tehnična in družbena infrastruktura ne deluje, pravni sistem je odsoten, oskrba je kaotična in podrejena logiki trenutnega preživetja ipd.). Poleg tega so pomembni tudi formalni vidiki: na primer razglasitev izrednih razmer in uvajanje posebnih ukrepov, različne oblike tujega formalnega skrbništva (na primer mirovne sile), resolucije in podobni formalni ukrepi na ravni prizadete države, ali pa / oziroma in mednarodne skupnosti (OZN, OVSE ali kak drug dejavnik na mednarodni ravni).

Drugi korak proučevanja kriznih območij je coniranje. V tej fazi je treba določiti cone različne intenzivnosti konfliktov oziroma njihovih posledic. Dejansko gre za regionalizacijo konflikta. Najlažje je določiti cono neposrednih spopadov - »gorišče«; to so tista ozemlja, na katerih so neposredno potekali (ali še potekajo) spopadi med sprtimi stranmi. V nekaterih 
primerih je to zaradi neenakomerne intenzivnosti spopadov ob splošno prisotnih napetostih to sicer težko; tedaj vzamemo najprimernejšo politično-teritorialno enoto. Drugi, navadno precej obširen teritorij je »cona mobilizacije«. To je ozemlje, ki zaradi tesne politične, kulturne, gospodarske navezanosti na "gorišče» (navadno tvorita skupno administrativno enoto, npr. državo) in prispeva materialne in človeške potenciale in ima zaradi tega tudi občutne posledice, še posebej v strukturi in funkciji teh območij. Tretje območje je »cona škode«, ki je neposredna (poškodbe, valovi beguncev) in pogosto tudi posredna (na primer znaten izpad dohodka). Njen točen obseg je težko natančno določiti. Nadalje je mogoče vsaj približno določiti skrajni doseg konfliktov in njihovih posledic.

K tej fazi sodi tudi geografski oris območja; določiti je treba značilnosti površja, geoloških, kamninskih, klimatskih, hidrografskih, pedoloških prvin. Pozneje sledi opredelitev še družbenogeografskih elementov, kot so naselbinski sistem, demografska in socialna struktura prebivalstva, administrativna členitev ozemlja ter sorodne vsebine.

V tretji fazije potrebno identificirati dejavnike; torej sprte strani, ki so vpletene v konflikt. Teh »notranjih« (na ravni kriznega območja) navadno ni težko odkriti. Toda krizna območja so presečišča regionalnih in globalnih sil in ni ravno redkost, da utegnejo biti prostorsko zelo oddaljene države ali njihove politične in gospodarske elite celo ključni dejavniki oblikovanja kriznih območij. Ob tem je koristno ugotoviti parcialne interese posameznih vpletenih strani.

Istočasno je potrebno identificirati ključne vitalne točke na kriznem območju, posebej $\mathrm{v}$ coni spopadov in coni mobilizacije. To so lahko glavno mesto, regionalna središča, prometna vozlišča in transportni koridorji, območja pomembnih surovin in energentov, ne nazadnje pa tudi plodna zemljišča in vodni viri. Ugotovitev teh območijje ključnega pomena pri načrtovanju mirovnih operacij in tudi pri poznejši pacifikaciji kriznega območja, rekonstrukciji ključnih institucij in infrastrukture, politični in administrativni razdelitvi ozemlja ter gospodarski revitalizaciji območja.

Posebno poglavje proučevanja kriznih območij predstavlja analiza političnih in administrativnih meja, njihove geneze in trajnosti. Proučiti je potrebno potek mejne črte (morfološka analiza) ter preteklih in sedanjih funkcij meje.

Posebej pomembno je proučiti etnično / jezikovno / versko razporeditev prebivalstva in sicer tako geografsko (prostorsko) kakor tudi njihovo vertikalno (socialno) stratifikacijo. S tem odkrivamo tudi podlago najpogostejših konfliktov; večina sodobnih kriznih območij ima prav etnično (kulturno, jezikovno) in / ter versko ozadje. Pri tem je treba biti še posebej skrben in previden pri uporabi virov podatkov (različnih statistik); neredko so prav zanikanja obstoja posameznih etničnih skupin ključni razlog konfliktov. Ob tem je smiselno ugotoviti tudi čas, potek in vzroke množičnih selitev v preteklosti ali sodobnosti.

Potem sledi analiza poteka krize od začetnih zapletov do današnjega stanja. Kronologija se zdi sicer najbolj enostavna, vendar je obenem tudi zelo pomembna, saj nam prav zaporedje določenih procesov in stanj olajšuje presojo o vzrokih in posledicah ter osvetljuje razsežnosti krize.

Poseben pomen ima analiza posledic konfliktov in kriznih stanj. Te je potrebno najprej evidentirati, kasneje pa določiti tudi njihov kratkoročni in dolgoročni pomen oziroma vpliv. Posledice so zelo raznovrstne. Razvrstimo jih lahko v tri skupine: fiziognomske (vidni elementi v pokrajini), strukturne (razpoznavne prek analize stanja) in funkcijske (bistveno 
spremenjeno ali sploh ukinjeno delovanje infrastrukture, institucij ipd.). Te elemente površno spoznamo že pri opredeljevanju krize in njenem coniranju; tokrat se moramo posledicam, posrednim in neposrednim, podrobneje posvetiti. Sedaj jih ne obravnavamo zgolj kot enkraten pojav (dogodek ali stanje) temveč tudi v luči procesov, ki so se ob tem sprožili. Prav procesna naravnanost nas vodi do današnjih problemov v kriznih območjih. Medtem ko pravni izvedenci in diplomati razmeroma pogosto postavljajo zahteve po »vrnitvi v prvotno stanje« (stanje pred konfliktom), bomo ob poznavanju procesov težko pristali na to tezo preprosto zato, ker je bodisi nemogoča bodisi nesmiselna. Zato je tembolj pomembno ugotoviti, katere posledice so povratne (reverzibilne) in katere so nepovratne (ireverzibilne).

Posebno poglavje v proučevanju kriznih območij predstavlja geografska analiza mirovnih operacij. Čeprav so pri teh navadno v ospredju predvsem vojaški, varnostni in politični vidiki, ne kaže zanemariti t.i. prostorskega segmenta. Delovišče mirovnih operacij je zelo zapleten prostor z mnogimi začetnimi nejasnostmi. Poenostavljanje pogosto vodi $\mathrm{k}$ zanemarjanju navidez obrobnih pojavov, problemov in potreb, kar pa se utegne hitro maščevati z regeneracijo konflikta. Poleg tega imajo mirovne sile vrsto specifičnih prostorskih potreb in zanesljivo vplivajo na strukturo, fiziognomijo in funkcijo kriznega območja celo še potem, ko bodo že zdavnaj zapustili kontrolne točke, baze in druga rezervirana ozemlja. Tukaj ima geografija še veliko dela z iskanjem in opredeljevanjem optimalnih lokacij, ki naj bi poleg vojaško-varnostnih prvin upoštevali tudi njihov vpliv na regionalno strukturo kriznega območja in s tem povezane revitalizacijske možnosti. Proučevanje mirovnih operacij predstavlja sicer zelo obširno poglavje znotraj politične in vojaške geografije in bo potrebno o tej tematiki pisati posebej.

Mirovne operacije so namenjene vzpostavitvi in ohranitvi miru, pozneje pa predvsem integraciji v regionalne in mednarodne okvire; tokove, združenja in institucije. Obe tem je smiselno iskanje perspektiv in razvojnih možnosti, $z$ ali brez asistence mednarodnih dejavnikov, prav tako pa iskanje ovir in pasti, postavljanje svaril in omejitev ter oceniti primernost različnih (nameravanih, navadno s strani pravnih in političnih dejavnikov sproženih) ukrepov in pobud.

$\mathrm{Tu}$ je nabor nekaterih najpogosteje uporabnih postopkov in tematik, ki jih je v okviru političnogeografske študije kriznih območij smiselno oziroma potrebno uporabiti. Zaradi individualnosti kriznih območij kot specifičnih kulturno (antropogeno) preoblikovanih pokrajin je treba pri vsakem primeru posebej upoštevati še specifične lokalno pogojene elemente in dejavnike. Zelo dobrodošel je pri tem celovit regionalnogeografski pristop, seveda problemsko in procesno naravnan ter aplikativen.

\section{5. ŠTUDIJ PRIMERA: SEVERNA DALMACIJA - PRIMER POSTKONFLIKTNEGA OBMOČJA}

Območje Kninske krajine na Hrvaškem obsega predele visokega, redko naseljenega kraškega sveta vzhodne Like in nizkega mediteranskega krasa v severni Dalmaciji. Na okrog $7000 \mathrm{~km}^{2}$ obsežnem teritoriju je pred vojno prebivalo okrog 155.000 prebivalcev, od katerih je bilo okrog $65 \%$ Srbov ter blizu $10 \%$ »Jugoslovanov«. Srbsko prebivalstvo je 
naseljevalo te kraje v več valovih bega pred Turki in z oblikovanjem »Vojne krajine«, ki je imela v okviru Habsburške monarhije poseben status. Območje je bilo gospodarsko pasivno z močno tendenco trajnega in začasnega odseljevanja že od konca 19. stoletja dalje. Prek Kninske krajine potekajo zelo pomembne prometne poti, vendar domače prebivalstvo od tega ni imelo velikih koristi. Območje je zadržalo periferni značaj kljub nekaterim poskusom po drugi svetovni vojni, da bi z načrtno industrializacijo ohranili prebivalstvo doma. Razen Knina, pomembnega železniškega križišča, prevladujejo manjša lokalna središča in vasi. Med srbskim in hrvaškim prebivalstvom je prihajalo do trenj že v preteklosti; zlasti med drugo svetovno vojno, ko je ozemlje v celoti sodilo v okvir Neodvisne države Hrvaške (NDH). V jugoslovanski federaciji po drugi svetovni vojni je bilo zlasti na mesta $\mathrm{v}$ upravi, policiji, vojski in nasploh v javnih službah več Srbov kot Hrvatov. Zaradi selitve k obali je naraščalo število Srbov in »Jugoslovanov« v obalnih krajih: nedvomno zaradi gospodarske privlačnosti turističnega razvoja, ki pa je bil že zaradi konfiguracije obalne črte in njenega zaledja praviloma tesno navezan na ozek priobalni pas. Notranjost (ki sestavlja večino t.i. »krajine«) je ostala gospodarsko manj razvit, skromno opremljen z infrastrukturo in zato demografsko nazadujoč prostor.

Napetosti med Srbi in Hrvati so se proti koncu osemdesetih let stopnjevale ter že spomladi 1990 (t.i. »balvanska revolucija«) prešle v odkrite spopade. Obenem je zvezna vlada v tesni navezanosti na armado (JLA) skušala na mednarodni ravni zagotoviti nevmešavanje v jugoslovanske notranje zadeve, navznoter pa preprečiti oblikovanje opozicijskih sil, tako politično, vojaško in gospodarsko (Vodušek, 1996, 9-75). Tako je bila Hrvaška še pred razglasitvijo neodvisnosti razorožena in tudi že delno fragmentirana. Na upor »krajišnikov« je naglo reagirala zvezna armada in zavarovala cone spopadov tako, da je ozemlje poznejših »krajin« ločila od možnosti posegov hrvaške policije. V doktrini tako »zahodnih» kakor »vzhodnih« držav tistega časa je bila ohranitev političnih meja ena od temeljnih vrednot. Zato je bila intervencija jugoslovanske armade za mednarodne dejavnike sprejemljiva. V Sloveniji se je razvila $\mathrm{v}$ desetdnevno vojno, na Hrvaškem pa vodila $\mathrm{v}$ krvave medetnične spopade in štiriletno državljansko vojno. Krizno območje na Hrvaškem se je pričelo oblikovati po zelo značilnem scenariju razvoja kriznih območij: strukturna neravnovesja in napetosti med skupinami prebivalstva so vodila $\mathrm{k}$ lokalnim spopadom (izbruh krize). Te je skušala rešiti »domača« (tj. jugoslovanska) intervencija ter obenem preprečiti internacionalizacijo krize. Znotraj oblikovane »krajine« s sedežem v Kninu je potekalo »etnično čiščenje«, ki je vsebovalo množične poboje, pregon, različne oblike nasilja in uničevanje gospodarskih, stanovanjskih in kulturnih objektov nasprotne (hrvaške) strani. Tudi ne ravno neznatne mirovne sile niso preprečile genocida in materialnega uničevanja. V letih 1992-1993 se je ozemlje »krajine« razširilo proti zahodu in skoraj pretrgalo komunikacijo med osrednjo Hrvaško in Dalmacijo. Spopadi na meji ali v njeni bližini so povzročili dodatne ruševine, prometnice pa so opustele. Namesto tega so se uveljavile nekdanje stranske poti. Vse čvrstejša hrvaška obramba je prehajala v odločnejše napade in v nekaj manjših uspelih vojaško-policijskih operacijah vrniti manjša, a strateško pomembna ozemlja. Mednje sodi tudi osvojitev Masleniške ožine, prek katere je pozneje pričela graditi nadomestni most. Ko je hrvaška vojska pozno pomladi 1995 prodrla prek vzhodne Like do bosanske meje in deblokirala bošnjaško Cazinsko enklavo in se spojila z ozemljem pod nadzorom bosanskih Hrvatov v zahodni Hercegovini, so bili dani 
pogoji za preobrat. V skrbno pripravljeni ofenzivi »Nevihta« (hrv. »Oluja«) poleti 1995 je reorganizirana hrvaška vojska ob delni ameriški strokovni asistenci uprizorila zadnjo veliko vojaško operacijo na evropskih tleh, ki je imela več potez t.i. »bliskovite vojne«. V samo petih dneh je v celoti osvojila ozemlje »krajine«. Območje je zaradi vojaške operacije doživelo dodatno škodo, predvsem pa se je odselila večina srbskega prebivalstva. Številna naselja so povsem opustela (Pirjevec, 2001). Prišel je mir in Hrvaška je vzpostavila suverenost nad celotnim državnim ozemljem (v vzhodni Slavoniji nekoliko pozneje). Krizno območje je prenehalo obstajati kot območje konflikta, ostala je opustela pokrajina. Posebej je treba opozoriti na istočasne podobno dogajanje na tleh Bosne in Hercegovine (Burg, Shoup, 1999).

Hrvaško krizno žarišče se je nominalno zaprlo, saj država sama bdi nad nekdanjimi srbskimi območji. Vendar je kulturna pokrajina doživela velike spremembe v svojem izgledu, strukturi in funkciji. Na kratko jih lahko povzamemo:

- $\quad$ zaradi bojev in pregonov se je bistveno zmanjšalo število skupnega prebivalstva;

- zaradi odselitve predvsem mlade in zrele kvote prevladuje na območju predvsem staro prebivalstvo;

- $\quad$ etnična sestava prebivalstva posameznih naselij in območja v celoti se je bistveno spremenila; Srbi so tudi lokalno postali manjšina;

- $\quad$ pri prebivalstvu so ostale psihološke posledice vojne (vojni stres, izguba bližnjih, množična posilstva ipd.), ki se odpravljajo počasi;

- $\quad$ še vedno je prisotno tveganje min in drugih sredstev (veliko večino so že razminirali);

Zaradi demografskega nazadovanja se je močno spremenila gravitacijska moč starih lokalnih središč; tudi Knin, ki je sicer zadržal vlogo županijskega središča, je kot center šibak. Že med vojno se je zasnovalo prometno omrežje, ki se nekdanje »krajine« izogiba (na primer sedanj trasa avtoceste Zagreb - Split), čeprav je mestoma (npr. na masleniškem mostu) zaradi vetrovnosti promet pogosto močno oviran. Železniško omrežje zaradi skoraj prazne pokrajine nima vloge niti za oskrbo lokalnega prebivalstva, niti za gospodarski razvoj tega območja. Split je v veliki meri izgubil znaten del svojega luškega zaledja. Vračanje beguncev je počasno ne le zaradi političnih razlogov, temveč zaradi neprivlačnosti in gospodarske neperspektivnosti območja. Pogosto se povratniki preselijo na obalni, turistično in tudi sicer gospodarsko bolj perspektivni pas. Notranjosti se zaradi neprivlačnosti, pomanjkanja osnovne infrastrukture, strahu pred možnimi minami ipd. izogibajo tudi turistični tokovi; vendar bi bilo mogoče za posebne skupine gostov organizirati tudi neke vrste »adrenalinski« turizem. Stopnjevanje litoralizacije in s tem tudi verjetni nastop konfliktnih rab prostora v bolj zasedeni obalni coni. Zaradi neurejenih lastniških razmerij je adaptivnih posegov v naseljih in na področju prometne infrastrukture zelo malo. Ruševine ostajajo pomiki časa, vendar tudi povečujejo naselbinsko neprivlačnost teh območij za povratnike in za druge. Tudi investicij je prav zaradi tega zelo malo, posledično pa ni delovnih mest.

Območje je prepuščeno stihijskemu razkroju kulturne pokrajine, v kateri je zaraščanje poglavitni proces. Neprivlačnost območja se tako vrti v začaranem krogu. Demografsko in gospodarsko šibko ter infrastrukturno skromno opremljeno območje ima zelo majhne možnosti čezmejnega sodelovanja z ozemljem na drugi strani državne meje (območje bošnjaško- 
hrvaške federacije). Zato je mogoče utemeljeno pričakovati nadaljnjo strukturno slabitev in periferizacijo tega prostora na obeh straneh meje.

Območje je zaradi demografske izčrpanosti odvisno predvsem od »zunanje« pomoči; endogeni človeški potenciali so odločno preskromni. Vendar je to lahko tudi krepak argument (posebej v povezanosti z vprašanjem vračanja beguncev), da bi Hrvaška skušala pridobiti sredstva za zelo drago sanacijo območja iz mednarodnih (predvsem evropskih) virov, sama pa se še naprej usmerja v lastne primarne gospodarske in strateške cilje. V vsakem primeru je območje nekdanje »krajine« na Hrvaškem odvisno od tuje asistence.

\section{6. ŠTUDIJ PRIMER: KOSOVO - PRIMER TRAJNEGA KRIZNEGA ŽARIŠČA}

Kosovo sodi med najstarejša in najbolj zapletena krizna območja na svetu. Nasprotja med srbskim in albanskim prebivalstvom se vlečejo od obdobja, ko je srednjeveška Srbija klonila pred osvajalsko močjo Otomanskega imperija, torej od 15. stoletja dalje. Tedaj je srbsko prebivalstvo predstavljalo skoraj 90\% večino (Nikolić, Vučković, 1996). Sedaj je razmerje obrnjeno ali pa je delež albanskega prebivalstva še večji. Kosovo ima zaradi zgodovinskih in kulturnih razlogov za Srbe poseben pomen, zato je tudi njegovo očitno izgubljanje skozi zadnja desetletja pomenilo precejšnjo nacionalno travmo. Srbski strateški načrti od osamosvajanja izpod turškega imperija v 19. stoletju dalje je Kosovu poleg mitološke pripisovala tudi velik geopolitični pomen: namreč pot do morja (Rüb, 1999). Vendar se slednje ni nikoli resneje približalo uresničitvi in je bilo Kosovo prostor, ki se ga je bilo mogoče ogniti. Strateško so bilo pomembnejša velika rudna in energetska bogastva ter razmeroma dobri pogoji za kmetijstvo. V okviru nekdanje Jugoslavije se je Kosovo lahko ponašalo z nadpovprečno gosto poselitvijo, čeprav predstavlja gorati in hriboviti svet več kot tretjino površine. Na malo manj kot $11.000 \mathrm{~km}^{2}$ živi približno dva milijona prebivalcev. Kosovo sestavljajo tri tektonske kotline: Metohija, Kosovo in Malo Kosovo z vmesnim hribovjem Drenica. S treh strani je zaprto z visokimi gorami: na zahodu Prokletije, na vzhodu Šarsko gorstvo s Crno goro, proti Albaniji niz skoraj $2000 \mathrm{~m}$ visokih gora in deloma še na severu s Kopaonikom. Edino na vzhodu se odpira proti dolini Južne Morave.

V turškem obdobju je imelo albansko - večinoma islamske veroizpovedi - gospodarske, politične in kulturne prednosti. Njihovo število se je povečevalo tudi zaradi dveh velikih selitev Srbov ter zaradi nasilja nad njimi. Na njihova mesta se je naseljevalo predvsem albansko in turško prebivalstvo. Potem ko je Srbija v balkanskih vojnah 1912-1913 osvojila območje današnjega Kosova in Makedonije, se je pričel obraten etnični proces, bilo je več poizkusov srbske in črnogorske kolonizacije ter pritiskov na albansko in turško prebivalstvo. Slednje se je v znatni meri odselilo kmalu po balkanskih vojnah ter po prvi svetovni vojni. Tako srbska kot albanska stran sta v svojem razvoju nacionalne ideje obravnavali Kosovo za svoje. Med drugo svetovno vojno je večino z Albanci naseljenega teritorija sodila v okvir albanske marionetne države pod italijanskim varstvom, kar je utrdilo nacionalna nasprotja med Albanci in Srbi. Po drugi svetovni vojni je Kosovo dobilo nekaj avtonomije, ki pa Albancem ni zadoščala. Iz Albanije se je na Kosovo priselilo precej beguncev izpod radikalnega komunističnega 
režima Enverja Hoxhe. Zaradi tega, odseljevanja Srbov proti severu in opazno višje rodnosti albanskega prebivalstva se je delež slednjih naglo povečeval (Mišović, 1987). Gospodarske investicije v pokrajino so bile večinoma neuspešne. Leta 1974 so z novo ustavo Albanci dobili vrsto možnosti na področju uprave, izobraževanja in kulture (Rajović, 1985). Vendar se je hkrati stopnjeval tudi srbski pritisk in skušal omiliti etnične učinke nagle demografske rasti albanskega prebivalstva. Konflikti so tako ostajali ves čas prisotno dejstvo, problem, ki so ga zaradi vrednote bratstva in enotnosti vztrajno pometali pod preprogo (Albanci, 1984). Od osemdesetih let dalje so bile demonstracije Albancev konstanten pojav, ki ga je skušala Jugoslavija vojaško in policijsko zatreti. Obe strani sta se obtoževali nasilja. Albanci so zahtevali republiko. Prav »kosovski problem« je omogočil nagel politični vzpon Slobodana Miloševića, ki je pozneje avtonomijo Kosova odpravil. Albanski odpor na različnih področjih se je selil v ilegalo. Po pričetku razpada Jugoslavije je marsikdo pričakoval, da se bo odprla najprej prav kosovska fronta. Toda Kosova tedaj ni zajela državljanska vojna, temveč je ostalo v senci tedaj mnogo intenzivnejših spopadov na Hrvaškem in v Bosni in Hercegovini. Pozornost je pričela spet pritegovati po Daytonskem miru leta 1995. Že prej se je oblikovala albanska gverila in skušala v manjših akcijah osvojiti nekatere predele Kosova (predvsem Drenico). Osvobodilna vojska Kosova (OVK) se oblikovala iz različnih kadrov, ki so se kalili tudi na nekaterih jugoslovanskih bojiščih (Latawski, Smith, 2003), oskrbovali pa prek ilegalne trgovine z orožjem, ki je spričo kaotičnih razmer na bojiščih Hrvaške, Bosne in Hercegovine ter ob kolapsu Albanije razpolagal z velikimi količinami orožja. Srbska (jugoslovanska) vojska je mejo z Albanijo učinkovito nadzirala. Izdatno finančno podporo so albanske organizacije dobivale prek dobro povezane albanske emigracije. Med Albanci je bilo več struj, ki so se močno razlikovale glede političnega in vojaškega koncepta (Petritsch, Kaser, Pichler, 1999) čeprav so imele razmeroma enoten končni cilj: popolno neodvisnost Kosova. Nemiri v zahodni Makedoniji (kjer Albanci predstavljajo četrtino prebivalstva) so pripeljali v državo mednarodno misijo (opazovalce), pozneje pa še manjše ameriške vojaške sile. Razbremenjena na hrvaških in bosanskih bojiščih se je jugoslovanska armada v večji meri posvetila Kosovu, kjer se je dejavnost OVK močno povečala. Na Miloševićevo vlado je pričela pritiskati tudi zveza NATO, da bi izsilila od nje vojaški nadzor celotne države. Geopolitične razmere v svetu so s pasivno držo Rusije povsem osamile Jugoslavijo. Pomladi 1999 se je pričela načrtovana vojaška akcija letalskih sil NATO (Latawski, Smith, 2003). Toda načrtovana nekajdnevna rutinska operacija se je razvlekla $v$ dvainosemdesetdnevno bombardiranje ne le vojaških, temveč predvsem gospodarskih (industrijskih) in infrastrukturnih objektov, povzročila večinoma civilne žrtve, medtem ko je srbski policiji in vojski uspel pregon Albancev. Skoraj 700.000 jih je začasno zapustilo domove in reke beguncev so preplavile obmejna območja Makedonije, Albanije in Črne gore. Srbska vojska je morala zapustiti Kosovo, ki je postalo mednarodni protektorat pod misijo UNMIK in razdeljeno na pet con: ameriško, angleško, nemško, francosko in italijansko. Albanski begunci so se vrnili, veliko Srbov pa je Kosovo zapustilo; preostali so se zaprli v enklave (Pirjevec, 2001, 532-549). Kosovo varujejo močne vojaške sile, mirovni proces je v domeni OZN, civilno upravo naj bi prevzela EU. Družbene in prostorske razmere so se zaradi dolgotrajnih konfliktov in vojaškega posega NATO močno spremenile, prav tako pa tudi njegov mednarodni značaj. Kosovo je ostalo trajno krizno žarišče. 
Dolgotrajne napetosti in več kot četrt stoletja odkritega konflikta je pustilo v družbi, pokrajinski strukturi, gospodarstvu in političnih okoliščinah globoke posledice, ki kratkoročno in dolgoročno vplivajo ne le na samo podobo in funkcijo Kosova, temveč tudi na sosednje pokrajine. V družbeni strukturi kosovskega prebivalstva so očitne številne spremembe. Prišlo je do nagle spremembe etnične sestave prebivalstva. Multietnično Kosovo postaja homogeno - albansko. Pri tem albanski nacionalizem posega proti vsem, ne le Srbom in Črnogorcem. Oblikuje se teritorialna segregacija, saj srbsko prebivalstvo ostaja zgolj še v varovanih enklavah, podobne tendence pa kažejo tudi druge etnične skupnosti. Hitro socialno razslojevanje albanskega prebivalstva je pogosto povezano z ilegalnimi gospodarskimi dejavnostmi in tradicijo rodovnih skupnosti, ki se ohranjajo tudi pri urbanem prebivalstvu. Posebej na podeželju ostajajo močne patriarhalne vezi, zaradi česar se povečujejo tudi razlike med mestom in podeželjem. Izobraževanje je po odpravi avtonomije potekalo $\mathrm{v}$ ilegali. V skromnih učnih pogojih je pridobil diplome večji del albanske mlade generacije. Zato so velike razlike med diplomo in stvarnimi operativnimi znanji, še posebej na tehničnem, medicinskem in naravoslovnem področju (ker bi potrebovali večjo tehnično podporo med izobraževanjem). Odseljevanje izobraženih in usposobljenih kadrov je konstanten proces. Odsotnost zdravstvenih in socialnih dejavnosti je spodbudilo zatekanje ljudi v okvire razširjenih družin oziroma rodovne organiziranosti in tako krepilo v bistvu elemente agrarne družbene organiziranosti v postmoderni dobi. Ta organiziranost predstavlja precejšnjo oviro vzpostavljanju moderne državne organiziranosti na področju družbenih odnosov. Ilegalne dejavnosti, $\mathrm{v}$ katere je bila albanska družba potisnjena zaradi pritiskov jugoslovanskih oblasti, in predstavljajo strategijo preživetja skupnosti v kriznih razmerah, je odlično gojišče organiziranega kriminala. Slednje predstavlja izjemno hudo breme vsake družbe in državne organizacije. Kosovo je veljalo za najmanj razvito območje v nekdanji Jugoslaviji. Odprti konflikti in njegove posledice so na področju gospodarstva povzročile vrsto sprememb. območje je bilo dalj časa izključeno iz legalnih gospodarskih tokov in tudi še sedaj je čutiti veliko previdnost pri vstopanju gospodarskih družb na Kosovo. Investicije so zelo skromne in prihajajo večinoma iz držav, ki so neposredno udeležene pri vojaškem in civilnem mirovnem procesu. Na območju Kosova ne deluje enoten finančni sistem, zaradi česar je poslovanje v mednarodnem prometu omejeno. $\mathrm{V}$ prometu so različne valute, med katerimi prevladujeta evro in ameriški dolar; dinar (območje še vedno formalno sodi v okvir Srbije in Črne gore) pa je plačilno sredstvo le v srbskih enklavah. Davčni sistem je zaradi močne navezanosti na lokalne in rodovne okvire ter ilegalno poslovanje cele generacije $\mathrm{v}$ preteklosti šele $\mathrm{v}$ povojih, bančništvo in zavarovalništvo pa je kljub prizadevanjem razmeroma skromni panogi (prav na tem sektorju se pričakujejo perspektive). Oskrba (solidna) je navezana predvsem na zunanjo (legalno in ilegalno) trgovino, celo pri sadju in zelenjavi. Prisotne mirovne sile (skupaj nad 30.000 ljudi) pomenijo znaten vir dohodka kosovskemu gospodarstvu in posameznikom. Energetska oskrba je izjemno skromna in predvsem neorganizirana. Električna energija prihaja bodisi iz uvoza, ali pa jo proizvajajo uporabniki sami s pomočjo motornih agregatov. Velikanske elektroenergetske kapacitete (zelo bogata ležišča rjavega premoga in lignita ter termoelektrarne v Obiliću) stojijo. Skrb za komunalni sistem je minimalna. Prometno omrežje je iz preteklosti in se minimalno vzdržuje, oskrba z vodo je vezana večinoma na lokalne vire (tudi zaradi nevarnosti sabotaž, odvajanje odplak je prepuščeno uporabnikom. Zaradi tega so 
okoljske grožnje in obremenitve lokalno zelo velike, nadzor pa ni vzpostavljen.

Koriščenje naravnih bogastev (pesek, mestoma premog, vodna sila in voda, les ipd.) je pogosto nenadzorovano in stihijsko, poraba teh dobrin pa včasih zelo neracionalna. Industrije je zelo malo; za lokalne potrebe jo nadomešča obrt. Turizma je zaradi obubožanosti domačega prebivalstva ter prebivalstva v bližnjem zaledju, močno prisotne tradicije zaprte družbe in slabega slovesa (območje varnostnega tveganja) ter ne nazadnje tudi slabih prometnih zvez zelo malo. Kmetijstvo je močno nazadovalo. Zaradi varnostnih tveganj in večjih priložnosti v mestu so nekatera podeželska območja (zlasti tista, na katerih je prej živelo srbsko prebivalstvo) opuščena, medtem ko jih v bližini mest (najboljši pogoji!) naglo in stihijsko uničuje divja urbanizacija. Namakalni sistemi, ki so v preteklosti ponekod omogočali intenzivno kmetovanje, marsikje ne delujejo več. Domači trg kmetijskih proizvodov je šele v zasnovi in domačim proizvodom konkurirajo uvoženi iz Albanije, Srbije, Grčije, Turčije ali celo Italije. Ta gospodarski paradoks predstavlja hudo oviro razvojnim perspektivam Kosova v celoti.

Poleg ruševin in drugih prič nedavnih spopadov in napadov so na Kosovu prisotne še druge prostorske posledice, značilne za krizna območja. Tako je močno spremenjen način poselitve in naselbinska struktura. Zaradi varnosti so nekatera podeželska območja, zlasti tam, kjer so bili prej Srbi, močno poškodovana ali pa so sploh povsem opustela. Nasprotno pa se je delež mestnega prebivalstva močno povečal tudi zaradi velikega povratnega vala beguncev, ki so se rajši odločili za življenje v primestjih. Nekateri se nimajo kam vrniti in so prav tako zasedli prenaseljene mestne robove. Na ta način se odvija posebna, nenačrtovana divja urbanizacija (zaradi tega je Priština skoraj podvojila število stalnega prebivalstva v nekaj letih). Srbsko prebivalstvo se je zgostilo v varovanih enklavah. Število prebivalstva se zaradi zelo visoke rodnosti ni zmanjšalo, temveč se še naprej povečuje. Gostota prebivalstva je sedaj še bolj neenakomerna, a v povprečju zelo visoka (nad 200 prebivalcev na $\mathrm{km}^{2}$ ). Zaradi nekontrolirane rabe zemlje, naravnih bogastev in drugih življenjskih virov je okolje ogroženo in strukturno osiromašeno. Nevarnost erozije je močno povečana na nagnjenih površinah. Pokrajinske prvine (posebej vodni viri) so mestoma močno obremenjeni. Urbanizacija je najbolj nekontrolirana na območjih »nikogaršnje zemlje« (nejasne lastninske zadeve), še posebej v okolici mest. Tako rastejo stanovanjske hiše posebej na mestnem robu, na ravninskih (nekdaj najboljših kmetijskih) zemljiščih, ter znotraj mestnega ozemlja, kjer se širijo na še proste parke, zelenice ipd. Vse to daje videz večje gostote in neurejenosti. Propadanje podeželske kulturne pokrajine zaradi odseljenega prebivalstva (vzroki odselitve so različni) ter celo neperspektivnosti kmetovanja (kar je pri tako visoki gostoti hud paradoks). Načrtovanja prostorskih ukrepov je zelo malo; prevladujejo zasebne in lokalne iniciative. Prostorsko obnašanje je prilagojeno trenutnim varnostnim razmeram in iznajdljivosti ter iniciativnosti posameznikov ali skupin. Razmeroma številčne mirovne sile (skupaj okrog 30.000) potrebujejo svoje posebne cone, ki so zgoščene v bližini večjih naselij in prometnic. Pri Uroševcu (alb. Ferizaj) gradijo veliko vojaško bazo Bondsteel.

Dolgotrajna kriza in spopadi so povzročile tudi velike spremembe $\mathrm{v}$ teritorialni in politični organiziranosti Kosova. Območje je sedaj pod varstvom prehodne uprave (UNMIK: United Nations Mission Interrim for Kosovo) ter mirovne sile pod vodstvom zveze NATO - KFOR (Kosovo Force), čeprav je formalno v okviru Srbije in Črne gore. Vendar nimajo 
organi te države skoraj nobenega vpliva na odločitve kosovske vlade in UNMIK-a, niti je ne obvladujejo davčno, fiskalno ali medijsko. Na multilateralni ravni potekajo pogajanja o bodočem statusu nekdanje avtonomne pokrajine. Kosovo je operativno razdeljeno na pet varnostnih con - sektorjev pod nadzorom ZDA, Francije, Velike Britanije, Nemčije in Italije. V pasu proti Črni gori in Srbiji je pet kilometrski varnostni pas, ki je kosovska različica »nikogaršnjega ozemlja«. Varnostne sile s težavo ohranjajo krhko varnostne razmere, usposabljajo domače (multietnične) varnostne sile (predvsem policijo) in nadzorujejo domačo vlado ter jo usposabljajo. Skrbništvo ohranja mir in omogoča minimalno delovanje javnih sektorjev, vendar je časovno omejeno in podvrženo hitrim konceptualnim spremembam. Pri revitalizaciji imajo »politične« teme odločno prednost, kar pa odriva nekatere hude probleme (npr. prostorski razvoj in upravljanje z viri in infrastrukturo) preveč v ozadje. Danes nerešeni problemi preteklosti bodo veliko breme in morda tudi razlog lokalnih konfliktov $\mathrm{v}$ prihodnosti.

Kosovo ostaja trajno krizno žarišče. Morda bodo njegovo geopolitično konfiguracijo dokončno spremenile šele spremembe političnih meja: aksiom o nespremenljivosti v Evropi se bliža tej usodni odločitvi. Vendar pa samostojnost Kosova in njegova morebitna poznejša združitev z Albanijo še ne bo pomenila konca travm, predvsem ne za srbsko skupnost, ki je bila zadnje dve desetletji globalno videti kot glavni dejavnik konfliktov, lokalno in v končnih posledicah pa se nahaja v vlogi žrtve.

\section{ZAKLJUČKI}

Krizna območja predstavljajo poseben, toda razmeroma znaten del zemeljskega površja in zadevajo skoraj pol milijarde ljudi, zgolj beguncev je skoraj 40 milijonov. Geografsko proučevanje se je kriznih območij doslej precej izogibalo, pogosto tudi zaradi zadrege, ki izhajajo iz slabega poznavanja teoretičnih postavk o teh pojavih ter pomanjkanja specifičnih geografskih metod. A vendar lahko že kompleksen regionalnogeografski pristop prinese veliko spoznanj o fiziognomiji, strukturi in funkciji pokrajine, ki je zaradi različnih razlogov znašla v viharju medetničnih konfliktov in različnih drugih nasprotij. V prispevku so predlagane vsebine in načini bolj sistematičnega spoznavanja kriznih območij, ki bodo uporabnikom - geografom omogočale uspešnejše soočanje s to sicer precej zapleteno političnogeografsko (in nikakor ne samo to!) materijo. Ob spraševanju o vzrokih in posledicah se znajdemo pred več kot stoletje staro Ratzlovo tezo, da močne sile vedno iščejo svoj življenjski prostor; danes bi to lahko prevedli v »življenjske vire«. Na drugi strani je vrsta trditev, da je povečano število kriznih območij po svetu rezultat spopadov med velikimi kulturnimi poli: spopad kultur in civilizacij. Čeprav ne moremo do konca razrešiti te dileme, bo tudi pojasnitev strukturnih in funkcijskih značilnosti kriznih območij, vključujoč tudi iskanje perspektiv prihodnjega razvoja, verjetno zadostila geografski radovednosti pri bolj sistematičnem raziskovanju kriznih območij po svetu. 


\section{Literatura}

Albanci. 1985. Cankarjeva založba, Ljubljana.

Atlas of the Middle East. 2003. National Geographic, Washington.

Banac, I., 1984. Nacionalno pitanje u Jugoslaviji, Globus, Zagreb.

Birnbaum, M., 2002. Kriesenherd Somalia, Heyne Verlag, München.

Brown, A., 1985. Modern Warfare from 1939 to the present Day, Orbis. London.

Burg, S.L., Shoup S., 1999. The War in Bosnia and Hercegovina, Armonk, New York.

Der Fischer Weltalamanch 2003. Fischer Verlag, Frankfurt am Main.

Der Fischer Weltalamanch 2005. Fischer Verlag, Frankfurt am Main.

Hiro, D., 2003. The Essential Middle East, Caroll \& Graf Publishers, New York.

Hupchick, P.H. D., Cox, E.H., 2001. The Palgrave Concise Historical Atlas of The Balkans, Palgrave, New York .

Ewans, M., 2001. Afghanistan, Harper-Collins Publishers, London.

Eberhardt, P., 2003. Ethnic Groups and Population Changes in Twentieth Century Central Eastern Europe, Armonk, New York.

Fromkin, D., 2001. A Peace to End All Peace, Henry Holt and Company, New York.

Gilbert, M., 2002. The Routledge Atlas of Russian History, London-New York, III.izdaja.

Grobe-Hagel, K., 2001. Tschetchenien: Rußlands langer Krieg, ISP, Köln.

Grošelj, K., 2006. Gorski Karabah - mir ali vojna, Slovenska vojska, letnik 14, št. 9, Ljubljana, 28-29.

Hofbauer, H., 2001. Balkankrieg. Zehn Jahre Zerstörung Jugoslawiens, Promedia, Wien.

Huchthausen, P., 2003. America s Splendid Little Wars, Penguin Books, London.

Imbusch, P., Zoll, R. (ur.), 1999. Friedens- und Konfliktforschung, Leske-Budrich Verlag, Opladen.

Jambrek, P., 1980. Od plemena do države, DZS, Ljubljana.

Klemenčič, M., Žagar, M., 2004. Jugoslavia's Diverse Peoples, ABC Clioh, Denver.

Latawski, P., Smith, A.M., 2003. The Kosovo crisis and the evolution of post-cold War European Security, Manchester University Press, Manchester.

Lozinšek, M., 2004. Kašmir-od raja do vojne, Geografski obzornik, letnik 52, št. 3, Ljubljana, 11-17.

Mišović, M., 1987. Ko je tražio Republiku Kosovo 1945-1985, Narodna knjiga, Beograd .

Natek K., 2000. Države sveta, Mladinska knjiga, Ljubljana.

Nikolić, G., Vučković, M., 1996. Stanovništvo Kosova u razdoblju od 1918 do 1991, Slavica \& Carniola Varlagsbuchhandel, München.

Nohlen, D., 2000. Lexikon Dritte Welt, Rowohlt Taschenbuch Verlag, Reineck bei Hamburg. Petritsch, W., Kaser, K., Pichler, R., 1999. Kosovo - Kosova, Wieser Verlag, Klagenfurt.

Pirjevec, J., 2001. Jugoslovanske vojne 1991-2001, Cankarjeva založba, Ljubljana.

Prebilič, V., 2006. Zakaj vojne v Afriki?, 1. del, Slovenska vojska, letnik 14, št. 7, Ljubljana, 27-29.

Prebilič, V., 2006. Zakaj vojne v Afriki?, 2. del, Slovenska vojska, letnik 14, št. 8, Ljubljana, 25-27.

Rajović, R., 1985. Autonomija Kosova, Izazov, Beograd. 
Reinhart, T., 2003. Israel/Palestine: How to end War of 1948, Seven Stories Press, New York.

Rumley, D., Minghi, J.V., (ur.), 1991. The Geography of Border Landscapes, Routledge, London.

Schneckener, U., 2002. Auswege aus dem Bürgerkrieg, Suhrkamp Verlag, Frankfurt am Main. Seton - Watson H., 1980. Nacije in države, Delo, Ljubljana.

Smith, D., 2003. The Atlas of War and Peace, Earthscan Publications, London.

Steininger, R., 2003. Der Naheostkonflikt, Fischer Verlag, Frankfurt am Main.

Strohmeier, M., Yalçin-Heckmann, L., 2000. Die Kurden, Verlag C.H. Beck, München.

Tunjić, F., 2004. Vmesna Evropa. Konfliktnost državnih teritorialnih meja, zbirka Annales, Koper.

Vejnović, D., 1971. Od plemen do narodov v Afriki, DZS, Ljubljana.

Veliki geografski atlas Jugoslavije, 1987, Liber, Zagreb .

Vodušek, V., 1996. Balkanska tretja vojna, Delo, Ljubljana.

Zupančič, J., 2005. Geografski vidik kriznih območij, Geografski obzornik, letnik 52, št. 3, Ljubljana, 4-10.

\section{GEOGRAPHICAL ATTEMPTS TO RESEARCH OF CRISIS AREAS}

\section{Summary}

In frame of political geography, the crisis areas are among »standard « topics. After the fall of Berlin wall and end of Cold War, the number of internal and external military conflicts increased evidently. It seems that the world powers opened new fronts in seeking their new position in world political order on one and that the changed character of national state pushed the internal ethnic communities to bloody local wars on the other hand. In any case, the crisis areas extended today near 18 million square (almost two Europes) $\mathrm{km}$ with more than 450 million people (like EU today); this includes near 40 million of refugees. Due to this statistics, the crisis areas have a strong impacts to world political map.

Which are crisis areas? These are territories which changed their cultural landscape quick and markable, worsened their structure of space and population and broken some functions. All those degradations counts to marginalization of this areas, even they are located at the crossroads of world political powers and represent neuralgic points of world policies. The typical crisis area has (normally) the ruines in settlements, different follows of military conflicts, killed or injured peoples, refugees, chaotic juridical situation, lack of public institutions and servicies, the dominancy of illegal economical activities, absence of investment, low level of personal and collective security, often used various forms of repression, strong reduction of educational system, medical care and social servicies, radical demographical changes with low birth rate and increased mortality and similar. The people tries to adopt to the mommental opportunities of survival first and could not make practically any plans for the future. That's why the functioning of crisis areas seems and really are chaotic ones; this caused later many problems in functioning of those landscapes. The paper brought brief overview of contemporary crisis areas on today's world political map, from Europe trough Asia and Africa to american continent. 
The crisis areas have - despite their individuality - some characteristical developmental stages: start from inicial confrontation, make an incident, than follow the outbreak. Manytimes, the countries try to marginalize the important of crisis first, until thic came not to the world scene and became internationalized. Than could follow the peacemaking proces (intervention): peacemaking and peacekeeping processes. The last two stages are dedicated to the reconstruction and revitalization of area as well as integration to the world community again. This chain could be broken anytimes. But this happen relatively rare; crisis areas show their persistence in conflict- and postconflictual situation.

How to make geographical analysis of crisis areas? The paper bring some suggestions and instructions how to make complexive geographical analysis (sourcing from political geography). This attempt based on systematic research of following topics: recognition of crisis situationa and area, delimitation and zones-making (regionalization), brief geographical description of the area, identification of factors, recognition of important strategic zones, inspection of inner (administrative) and outer (political) borders, structural analysis of ethnic-, religious- and/or linguistical characteristics, than chronological description, identification of the conseqiences (problems and processes) and last, but not least, the analysis of peace-makingkeeping processes (particulary spatial needs), together in searching for future perspectives, obstacles and conditions. Finally, the author ilustrate the characteristical development of two different crisis areas: North Dalmatia (Croatia) and Kosovo (South Serbia). 